\title{
Practice and Experience from the Optimization and Upgrading of Industrial Structure in Ruhr Industrial Region Germany for Reference
}

\author{
Lingna Mo, Hailin Zhu, Jia Liang and Miao Ding
}

\begin{abstract}
Optimization and upgrading of industrial structure for a country or an area's economic development, social progress and promoting the regional economic competitiveness and sustainable economic and social development have very important practical significance. In this paper, the author studies Germany Ruhr Industrial Area industrial structure optimization and upgrading of the practice and experience for reference, the regional industrial structure optimization and upgrading of our country has certain theoretical significance and practical guiding significance.
\end{abstract}

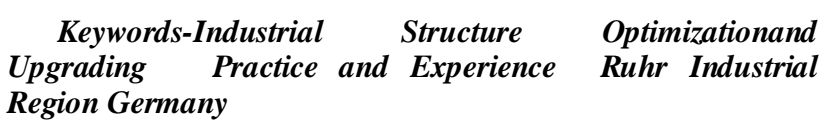

\section{A BRIEF HISTORY OF THE RUHR DEVELOPMENT}

\section{A. The Rise of Ruhr Industrial Region}

The formation of the Ruhr industrial region was with the "black gold" of coal resources, inseparable, it contained about 50 billion tonnes of coal reserves. From the 14th century there were records of coal mining, but mainly outcrop of coal seam in southern of the Ruhr area for simple primitive mining. It was not until the 19th century that coal mining production of the Ruhr in Germany was insignificant. After the middle of the 19th century, an unprecedented industrial revolution caused the Ruhr like gold rush, which in a short time had become a dream place for industrial workers. The word "Ruhr" into the official documents for the first time was the Treaty of Versailles at the end of the World War I. Under the treaty, Germany, as the defeated country, had to compensate France with the coal in Ruhr. The Ruhr region as a result of the introduction of 15 million miners and 45 million families, huge migration project to the Ruhr region brought economic leap for the first time. Many new chimney, boiler room, digging derrick and steel plant growing development, the Ruhr region of the original agricultural society landscape became completely different, by being an important industrial

Lingna MO: 1963-, Professor, Master of Economy and Management, Deputy Director of Department of Finance and Economy, Guangxi University of Science and Technology, China, the direction of research: Knowledge-driven economy and innovation management

Hailin Zhu: 1990-, Graduate students, Guangxi University of Science and Technology, the direction of research:
Knowledge-driven economy and innovation

Jia Liang: 1987-,Teacher, Lushan College of Guangxi University of Science and Technology, is mainly engaged in the accounting audit.

Miao Ding: 1990- Graduate students, Guangxi University of Science and Technology, the direction of research: Knowledge-driven economy and innovationregion in Europe. Later, there were a lot of eastern foreign workers to come here.

\section{B. The Ruhr Industrial Region Development}

During the two world wars, the Ruhr region became engine of German war of aggression, and reared arsenal responsible German foreign war, which was also allied bombing as an important goal. When World War II ended, the Ruhr industrial region was severely destroyed, also making the entire German economy develop slowly. In the process of economic recovery in post-war Germany, the Ruhr industrial development had been a priority for Germany to contribute to economic recovery.

With the development of cooperation coal and steel industry, the industrial structure and infrastructure of the Ruhr industrial region quickly returned to pre-war levels. From 1950 to 1958 , the coal production in the Ruhr region rose 20 percent, steel production increased by $30 \%$. Economic recovery in the Ruhr region again attracted a large number of immigrants. Not only in Germany, Ruhr mines also began recruiting large numbers of workers overseas, around the 1950 s, and 100 million immigrants entered the Ruhr region, because the Ruhr region GDP accounted for $12 \%$ share of the original Western Germany, making it become the strongest region of Germany's economic strength.

\section{The Recession of Ruhr Industrial Region}

But it did not last long. To the 1960s, The impact of cheap oil, natural gas and imported coal (the increased depth of coal mining, leading to high labor costs, imported coal from abroad even cheaper than the local coal), coupled with the international market for heavy industrial products declined in demand, the coal and steel industries of Ruhr Industrial Region was seriously challenged and seriously affected many related industrial sectors. A large number of smelters had to closed, causing hundreds of thousands of unemployed steelworkers and then a sharp decline in population of Ruhr Industrial Region, because there was no other employment choice but to leave their homes. According to statistics, in 1957, the Ruhr region had 141 coal mines, 490,000 coal miners, and the annual 
output of 120 million tons; in 1995, remaining 13 mines, less than 70,000 coal miners, and coal production to 40 million tons tight. Once glorious moment of big industrial era gone, Ruhr Industrial Region began to be called the backward areas in German.

\section{The Revitalization of Ruhr Industrial Region}

With the sharp decline and worsening image of the region, the voice of Ruhr region to revive the economy of glory and improve the international competitiveness was increasingly strong, which led to the transformation of traditional industries in Ruhr region. Transition measures include the joint or merger of the steel industry and expand the scope of market supply and marketing, and enhance international competitiveness; Some traditional polluting industries were limited production or shut down (such as coal production), and began to Proceed with the development of environmental technology, electronics, machinery and other emerging industries; at the same time, small and medium enterprises with technical innovation mushroomed. The service sector which was a long-term stagnation industry came from behind to get large-scale development. Linked with this was to establish a number of universities and research institutes having the world's most advanced technology capability, such as the Bochum University born in 1965 . These R \& D bases for the Ruhr region not only trained a large number of highly qualified technical personnel, but by virtue of its strong technological strength had become an important partner for Ruhr Industrial Region and became a new growth point of economic development.

\section{INDUSTRIAL RESTRUCTURING AND DEVELOPMENT}

\section{OF RUHR INDUSTRIAL REGION}

\section{A. Industrial Restructuring Policy}

To avoid Ruhr region turning into barren land and abandoned mine tunnel, from the 1980s, the German government began to implement regional economic adjustment including the structural transformation in Ruhr region. Mainly through the joint or merger of the steel industry to formed large steel companies with international competitiveness, develop machinery and equipment industry, automatic control technology, environment-friendly industry with German specialties, and encourage to develop the service industry. To promote these industries in a leading position in the high-tech competition, from the 1960 s, Ruhr region has created 14 universities and scientific institutions and the establishment of countless variety of science and technology parks, becomes the incubator of research and production.

\section{B. The Government's Policy Guidance and Financial Subsidies}

In industrial restructuring, Ruhr region began to diversify the direction of development of industrial structure, limit the old industrial development, actively promote the development of service industry, improve the investment environment of high-tech and R \& D facilities, enhance technological innovation and competitive advantage in the region, with the aid of the funds of the EU, German federal and state governments (such as the EU regional revitalization fund, the Ruhr region action plans, etc.). The German Federal government to give Ruhr mining subsidies from 14.7 billion euros in 1998 will be gradually reduced to 2.7 billion euros in 2005 . In order to attract more investment from the US chemical companies, the state government had taken a series of measures to simplify approval procedures, providing government with funding and flexible recruitment.

\section{Changes in Industrial Areas and Industrial Landscapes Cultural Tourism}

The development of tourism as the leading service industry has also become one of the key strategies of the Ruhr area transition. Ruhr region to invest in the development of tourism resources that left a large number of the industrial era factories, workshops and other industrial machinery and architecture memorial site (Indus. triedenkmalen) Government investment encourage local industrial and mining to transform into historical relics, and imformate a kind of unique style of industrial history museum in order to promote tourism service.

\section{RUHR SUCCESSFUL EXPERIENCE ADJUSTMENT OF}

\section{INDUSTRIAL STRUCTURE AND INSPIRATION}

\section{A. To Develop (a) Emphasis on Planning}

At the initial stage of development, Ruhr lacked respect for land use, urban layout, overall planning and environmental protection, resulting in deteriorating environmental quality areas, regional image severely damaged. In order to promote the coordinated development of the region, the German government enacted laws to set up the Ruhr coal district Development Association, as the Ruhr area's top planning agency. After that, they again expanded its powers by law, and has now become the joint institution of regional planning, the development of the mining area to make overall planning and co-ordination arrangements. Ruhr overall development plan for the adjustment of the economic and social structure of the Ruhr area played an important role in making the century-old industrial area once again full of vitality.

\section{B. Strengthen the Infrastructure Construction}

Ruhr area, built by road, rail and waterway transportation network, is Europe's most dense transport network and occupies $600 \mathrm{~km}$ highway district, $730 \mathrm{~km}$ federal highway, $1,190 \mathrm{~km}$ of rural roads criss-cross the region composed of the Ruhr highway net, making the region in any one place is not more than six kilometers from the motorway.

\section{To Conduct a Comprehensive Transformation of}

\section{Traditional Industries}

Over the years, the coal industry and the steel industry have been the development of two pillars of the Ruhr area, the economic structure is so aged that the economic growth rate is significantly lower than the Ruhr national average. From the beginning of the 1960s, under the 
auspices of the government, enterprises centralize and rationalize management. Coal and steel industries were traditional mergers and technological innovation, specialization and cooperation of enterprises to strengthen internal and between enterprises.

\section{Actively Cultivate New Industries}

In further explore the potential of existing industries, the Ruhr region will be of great potential for development of high-tech industries and the cultural industry as a key development in order to improve the competitiveness of the regional industry. There are:

\section{1) Health Engineering and Bio-Pharmaceutical industry:}

Ruhr area is one of the world's most concentrated hospitals, from the world's leading medical technology to traditional treatment methods, covering almost all of the medical field. Research institutions in the city, medical education institutions to provide technical support for the development of the pharmaceutical and bio-engineering, as well as to attract innovative enterprises in areas such as biopharmaceutical enter. Currently, the pharmaceutical industry absorbs a total of 280,000 jobs, and is the largest employment industry in the Ruhr area.

\section{2) Logistics Industry.}

Ruhr area is based on geographic conditions, transport and industrial heritage, pushing by the municipalities, as well as international logistics enterprises to participate in scientific research into developing logistics industry, at present, about 3,000 logistics companies, covering the Ruhr industrial value chain all aspects of employment for 18 million people.

\section{3) Chemical Industry.}

Ruhr region was a pioneer in the German chemical industry, chemical industry after the decline of tar, carbon Ruhr actively develop petrochemical and natural gas chemical products. Chemical products deep processing has a significant degree of backward linkages, stimulating the economic revival of the Ruhr area. New chemical products are safe, efficient, clean and recyclability. It improves the capacity of sustainable development.

\section{4) Cultural Industry}

Tourism and cultural industry is one of the main features of the Ruhr region to achieve economic transformation. In 1998, the Ruhr region developed a regional tourism plan, was known as the "Route of Industrial Heritage" tourist routes connecting 19 industrial tourism attractions, six national museums and 12 typical industrial towns. "Industrial Heritage" like a reflection of the coal mines, coking industry development, "textbook", lead people to travel for 150 years of history of industrial development. The development of industrial tourism in improving the regional function and image played a unique effect, and became a symbol of the Ruhr region's economic transformation

\section{E. Fully Support Role of Research Institutions and}

\section{Higher Education for Industrial Transformation}

Ruhr University has developed into Europe's largest industrial area in terms of density. In addition to specialized scientific research institutions, each university has a "Technology Transfer Center", thus forming a market application from the technical to the system. Meanwhile, the government encourages enterprises as well as enterprises and research institutions to cooperate in order to play a "group effect", and under such cooperation. And this cooperation development of projects to be grant funds. Currently, the region has 30 technical centers, 600 committed to the development of new technologies. Ruhr region in the transition process has always attention to environmental protection, pay attention to image. As a result of strong measures to improve the once heavily polluted environment, such as restrictions on emissions of polluting gases, the establishment of air quality monitoring systems. Today, the Ruhr area has become a beautiful environment green parks, elegant industrial park, not only improving the quality of life of local people, but also creating a clean and beautiful environment for the development of new industries.

\section{REFERENCES}

[1] The Industrial History of the Ruhr Area of Germany

[2] The Industrial History of Germany

[3] Germany 1964-2014 Statistical Yearbook 